\title{
Temporomandibular Disorder in Mosul City.
}

Baceer A Abdullah BDS, MSc (Lect)

\author{
Department of Oral Surgical Dentistry \\ College of Dentistry, University of Mosul
}

\begin{abstract}
Aims: To describe the subjectively perceived symptoms and frequency of the objective signs of the mandibular dysfunction and their severity by using Helkimo index ,age distribution and their relation to sex. Materials and methods: This study includes 450 TMDs patients, who admitted to TMJ clinic at college of dentistry in Mosul City, Helkimo index was used to assess the symptoms and signs of the TMDs and their severity. Results: It was found that TMDs most frequently affected the age group 2130 years. TMJ sounds (Clicking and Crepitation) were found as the most frequent symptoms $(71.5 \%)$ followed by difficulty in opening (29.3\%). No sex difference in relation to TMJ sounds was found $p>0.05$. Impaired TMJ function was the most prevalent sign (82.6\%). No sex difference in relation to ITF was found $p>0.05$. Concerning the distribution of the patients according to Ai (Anamenstic dysfunction index). It was found that 51 patients $(11.3 \%)$ were symptoms free (Ai0), 169 patients (37.5\%) reported mild symptoms (AiI) and 230 patients (51.1\%) complained from severe symptoms (AiII). No significant sex difference in relation to Ai was found $p>0.05$. Regarding the distribution of the patients in relation to $\mathrm{Di}$ (Clinical dysfunction index). This study reveals that 7 patients (1.5\%) were sign free (Di0), 114 patients $(25.3 \%$ ) with mild signs (DiI), 172 patients $(38.2 \%)$ with moderate signs (DiII)and 157 patients (34.8\%) with severe signs (DiIII). No significant sex difference in relation to clinical dysfunction index (Di) $p>0.05$ was found in this study. Conclusions: The age 21-30 years consider the high risk age group. The TMJ sounds were the most frequent symptoms. Severe symptoms (Ai II) and signs (DiIII) represents high percentages (51.1\%) and (34.4\%) respectively in a patients with TMDs in Mosul City.
\end{abstract}

Key words: TMDs, Helkimo index.

Abdullah BA. Temporomandibular Disorder in Mosul City. Al-Rafidain Dent J. 2007; 7(SpIss): 18S23S.

Received: 28/9/2006 Sent to Referees: 15/10/2006

Accepted for Publication: 21/11/2006

\section{INTRODUCTION}

Temporomandibular disorder (TMDs) is a collective term embracing abroad spectrum of clinical joint and muscle problems in the orofacial area. These disorders characterized primarily by pain, joint sounds and irregular or limited jaw function. TMDs is considered a distinct subgroup of musculoskeletal and rheumatological disorder and it represents major cause of nondental pain in orofacial region ${ }^{(1)}$.

Numerous clinical signs and symptoms have been attributed to TMDs, many of them are highly controversial and there was no complete agreement of symptomtology found in the literature ${ }^{(2)}$.

The common occurrence of various subjective symptoms and objective signs of mandibular dysfunction has been shown in several epidemiological studies ${ }^{(3-5)}$, only slight variation by sex has been reported in random populations ${ }^{(4)}$; while in other epidemiological study by Grosfeld et al at $1985^{(6)}$ among adolescents and young adults, revealed females significant overrepresentation in the groups of TMDs.

In terms of relation between the occurrence of mandibular dysfunction and age, high prevalence of such signs and symptoms have been reported among children ${ }^{(7)}$, adolescent ${ }^{(8)}$, adult ${ }^{(9)}$, and aged persons ${ }^{(10)}$.

Although there are many epidemiological studies done on nonpatient's population in Iraq ${ }^{(11,12)}$, only few studies were done in patients group ${ }^{(2)}$, it was decided to do this study in patient group with TMDs in Mousl City.

This investigation was one in series of studies of patients group with TMDs, who attended to TMJ clinic at College of Dentistry in Mousl City.

The aims of the present paper is to describe the subjectively perceived symp- 
toms, frequency of the of the objective signs of the mandibular dysfunction and their severity by using Helkimo index ${ }^{(13)}$, the age distribution and their relation to sex.

\section{MATERIALS AND METHODS}

This study includes 450 patients who admitted to oral medicine clinic at Mosul university during six years period (20012006).

The patients consisted of 271 females and 179 males, the age ranged $13-65$ years old. All patients diagnosed to have TMDs because the absence of other disease entities which account for their symptoms, patients were examined by author in order to reduce bias in the collection of the data, the mean age was 25.64 years. Helkimo index 1974 was used in this study to evaluate the signs and symptoms of TMDs and their severity numerically which important to determine the treatment need and to facilitate the comparison with other studies.

Most of the patients came to the college as referred by the dentists and self-referral, while other patients are referred by Rheumatologists and ENT specialists.

\section{RESULTS}

It was found that the age group (21$30)$ years were the most frequently affectted by TMDs in both genders as shown in Table (1).

Joint sounds (clicking and crepitateon) were found as the most frequent symptoms $(71.5 \%)$ followed by difficulty in opening $(29.3 \%)$, while luxation $(0.8 \%)$ and feeling stiffness $(0.4 \%)$ were the least frequent symptoms, reported by the patients as revealed by (Figure 1).

Impaired TMJ function (ITF) were found as the most prevalent sign (82.6\%) followed by pain on movements (PM) $(71.1 \%)$, while the least prevalent sign was the restricted mouth opening $>40 \mathrm{~mm}$ (MI) $(20 \%)$, as demonstrated by (Figure 2$)$.

The sex distribution in this study showed that no sex difference in relation to joint sounds $(\mathrm{x}=0.101, \mathrm{~d}, \mathrm{f}=1, p>0.05)$, also no sex difference was found in relation to ITF. $(x=1.053, d, f=2, p>0.05)$.

Figure (3) revealed the distribution of the patients in relation to sex and Anamenstic-dysfunction Index (Ai), 51 patients $(11.3 \%)$ were symptoms free (Ai0), more than one third of the patients had mild symptoms (AiI 37.5\%); while more than fifty percentages $(51.1 \%)$ of the patients complained with severe symptoms (AiII).

Although mild and severe symptoms were more frequent in females than males, no significant difference was found concerning the severity of symptoms. ( $\mathrm{x}=$ 4.259, $\mathrm{df}=2, p>0.05)$.

Figure (4) showed the distribution of the TMDs patients according to clinical Dysfunction Index (DI), seven patients $(1.5 \%)$ were sign free (Di0), 114 patients $(25.3 \%)$ with mild signs, and more than one third of the patients (172 patients ) having moderate (38.2\% DiII), and 157 patients had severe signs (34.8\% DiIII).

Although the number of the female patients were more represented than male patients in mild, moderate and severe signs, no significant difference was found $(\mathrm{x}=$ $6.533, \mathrm{~d}, \mathrm{f}=3, p>0.05)$.

Table (1) Distribution of TMDs Patients in Relation to

Age and Sex.

\begin{tabular}{ccccccc}
\hline Age groups & \multicolumn{2}{c}{ Male patients } & \multicolumn{2}{c}{ Female patients } & \multicolumn{2}{c}{ Total } \\
\hline $\mathbf{1 1}-\mathbf{2 0}$ & 47 & $(26.25 \%)$ & 54 & $(19.92 \%)$ & 101 & $(22.44 \%)$ \\
$\mathbf{2 1}-\mathbf{3 0}$ & 96 & $(53.63 \%)$ & 169 & $(62.36 \%)$ & 265 & $(58.88 \%)$ \\
$\mathbf{3 1}-\mathbf{4 0}$ & 27 & $(15.08 \%)$ & 29 & $(10.70 \%)$ & 56 & $(12.44 \%)$ \\
$\mathbf{4 1}-\mathbf{5 0}$ & 7 & $(3.9 \%)$ & 14 & $(5.16 \%)$ & 21 & $(4.66 \%)$ \\
$\mathbf{5 1}-\mathbf{6 0}$ & 0 & $(0 \%)$ & 3 & $(1.10 \%)$ & 3 & $(0.66 \%)$ \\
$\mathbf{6 1}-\mathbf{7 0}$ & 2 & $(1.11 \%)$ & 2 & $(0.73 \%)$ & 4 & $(0.88 \%)$ \\
\hline Total & 179 & $(39.8 \%)$ & 271 & $(60.2 \%)$ & 450 & $(100 \%)$ \\
\hline
\end{tabular}




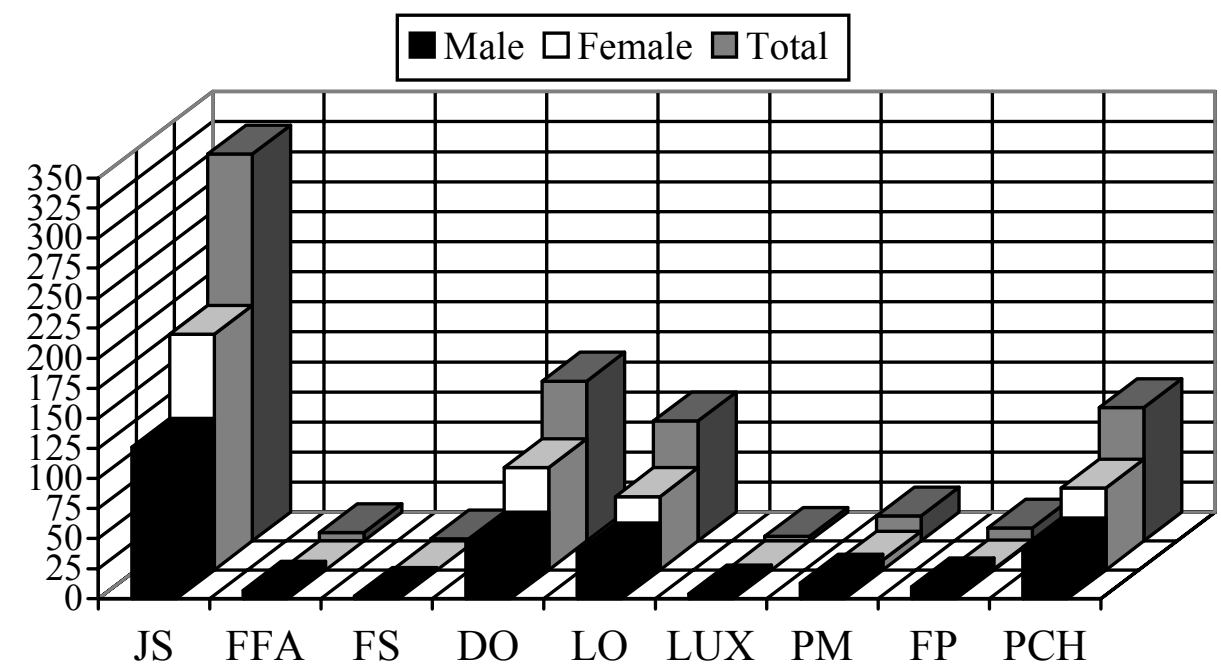

Figure (1): Relative Distribution of the Patients' Symptoms in Relation to Sex

JS: Joint sound, FFA: Feeling fatigue, FS: Feeling stiffness, DO: Difficulty in opening, LO: Locking, LUX: Luxation, PM: Pain on movement, FP: Facial pain, PCH: Pain on chewing.

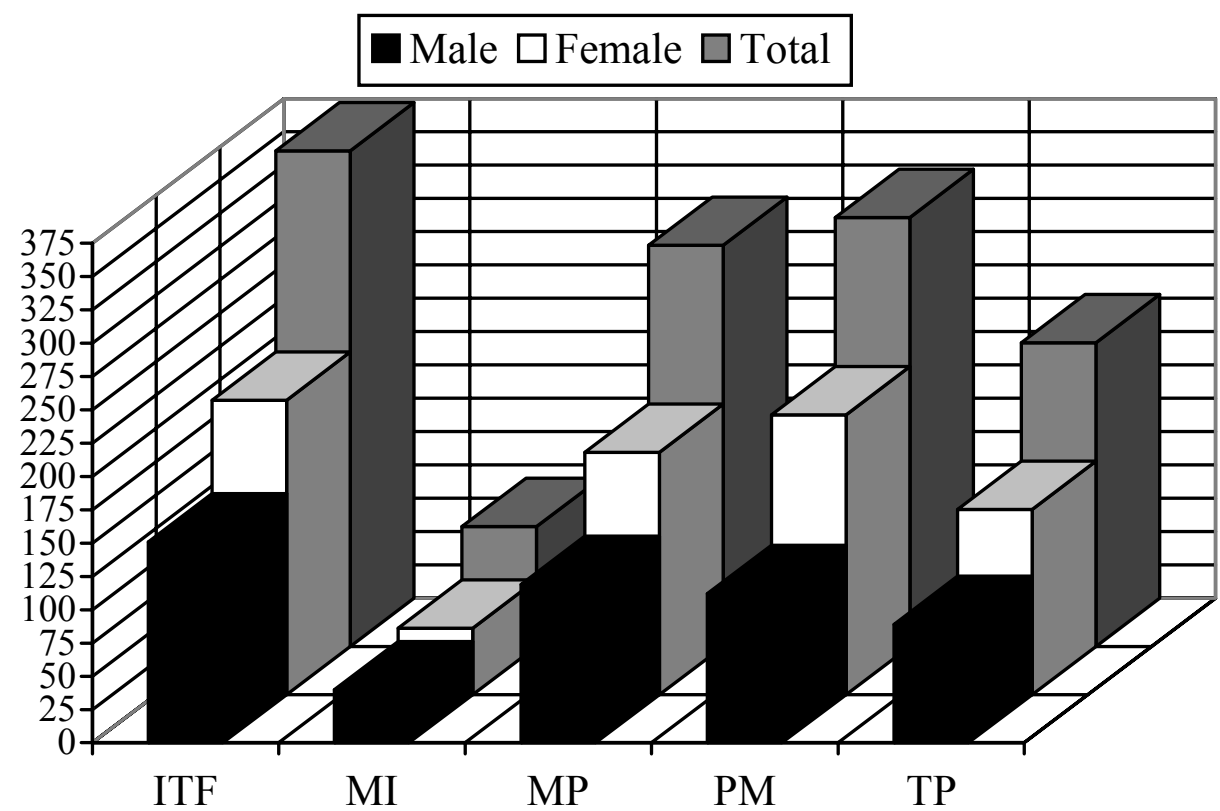

Figure (2): Relative Distribution of the Patients' Sign in Relation to Sex

ITF: Impaired Temporomandibular joint Function, MI: Mobility Index, MP: Muscle Pain, PM: Pain on Movement, TP: Temporomandibular joint Pain. 


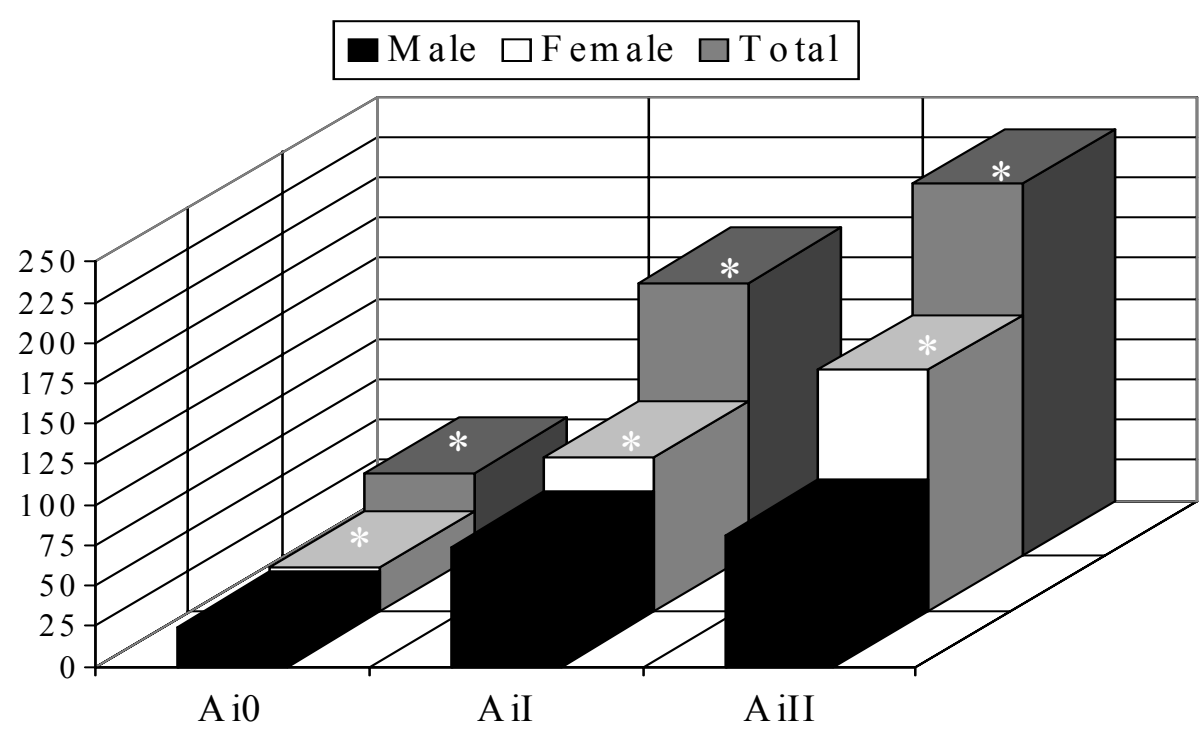

Figure (3): Patients' Distribution in Relation to Sex and Anamenstic Dysfunction index (Ai)

Ai0: No symptoms, AiI: Mild symptoms, AiII: Severe symptoms; $* \chi^{2}$ test between males and females $=4.258 ; \mathrm{df}=2 ; p$ value $=0.119$; Not Significant.

\section{a Male $\square$ Female $\square$ Total}

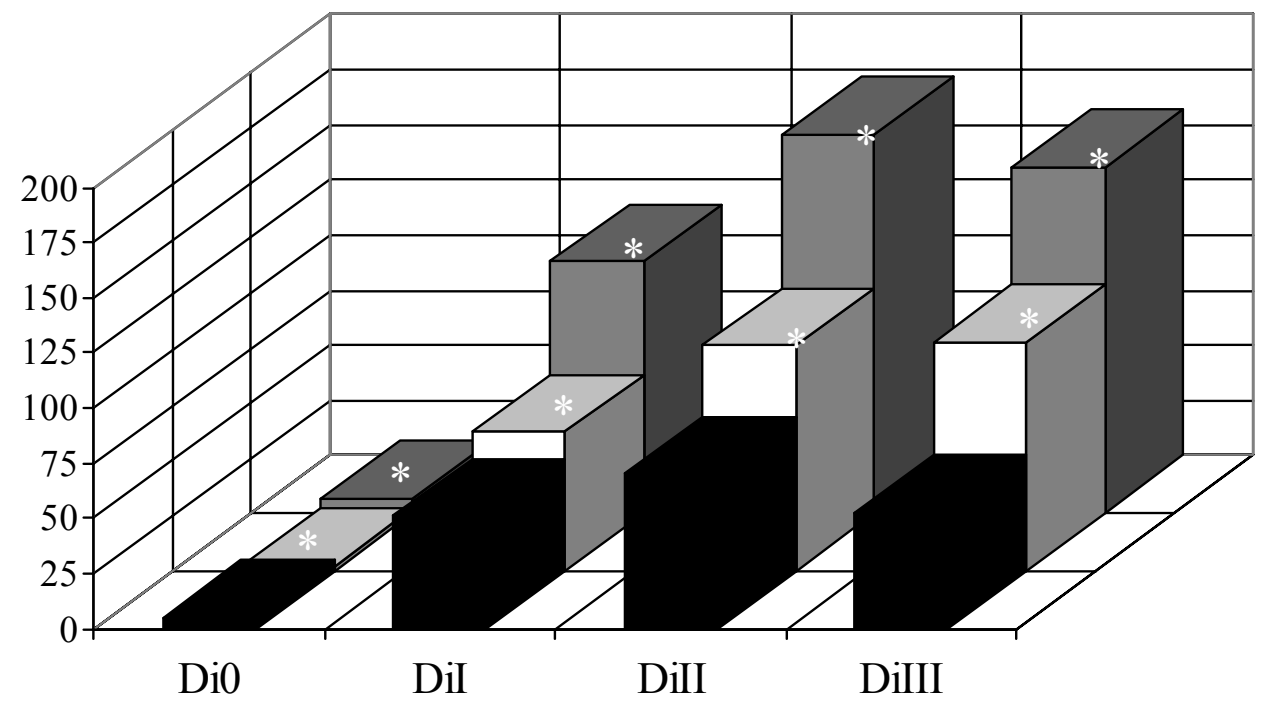

Figure (4): Patients' Distribution in Relation to Sex and Clinical Dysfunction index (Di)

Di0: No signs, DiI: Mild signs, DiII: Moderate signs, DiIII: Severe signs; $* \chi^{2}$ test between males and females $=6.533 ; \mathrm{df}=3 ; p$ value $=0.088 ;$ Not Significant 


\section{DISCUSSION}

In this study the young age group (21-30 years old) was found as the highest risk group, this finding was agreed with other studies ${ }^{(5,14-18)}$.

The lower prevalence of TMJ signs and symptoms in older age groups supported the probability of that most TMDs were self-limited ${ }^{(15)}$.

Helkimo concluded that there were no great difference with frequency in dysfunction between men and women in general population, he claimed that women attended the TMJ clinic seeking help more often than men did. The present study showed that females were predominate the males in TMDs $271(60.3 \%)$ to 179 (39.75) / 1.5-1 ratio, these difference may be attributed to physiological and hormonal factors that should be considered ${ }^{(1)}$. Our result was in agreement with studies done in United States ${ }^{(22)}$, were women represent 65\% and men 35\%; Canada ${ }^{(23)}$, England with ratio: $3.5-1^{(24)}$, Greece (3-1 ratio) ${ }^{(25)}$, and in Iraq ${ }^{(2)}$.

The most prevalent symptoms was the TMJ sounds (71.55), this finding agreed with the results of Agerberg and Carlsson ${ }^{(3)}$, who found that the joint sounds were reported significantly in sample of Swedish TMDs patients than in population ( $79 \%$ versus $38 \%$ ), and with the result of Grosfeld et al ${ }^{(6)}$, who reported that the TMJ sounds was $75 \%$. Some evidence suggested that the presence of joint sounds may be useful predictor of dysfunction ${ }^{(20)}$.

In this research the most prevalent sign was the ITF $(82.6 \%)$ and this result was agreed with study done in England (21), the researcher found the TMDs patients had significantly greater ITF $(79 \%$ versus $54 \%$ ) than matched a symptomatic individuals.

In spite that the number of the female patients were exceeding the number of the male patients in TMJ sounds, there was no statistical difference between the two groups $p>0.05$ and these results were agreed with other studies ${ }^{(5,7)}$.

Also no significant sex difference in relation to ITF was found in this study and this result disagreed with the results of other studies ${ }^{(5,6)}$.

Concerning the distribution of the patients according to Ai, this study reveal- ed that the severs symptoms Aill were more frequent in both gender than mild symptoms AiI, The finding of this study was consistent with that done by Schiff-man et $a l^{(26)}$, no sex difference was found in this study regarding the Ai at $p>0.05$, and this result agreed with other studies ${ }^{(5,27)}$.

Fifty one patients $(11.3 \%)$ were reported no symptoms as those patients were referred by physician and ENT specialist, for their headache and ENT problems with no obvious cause; and during examination of their TMJ a TMDs were found as a cause.

According to this study more than one third of the patients complained from moderate and severe signs $(38.2 \%$ DiII, $34.85 \%$ DiIII). This result agreed with the finding reported by Droukas et al ${ }^{(14)}$.

No sex difference concerning the clinical dysfunction $p>0.05$, this was in consistent with the result of Abdullah ${ }^{(12)}$.

In this research seven patients (1.5\%) were free of signs of TMDs, as those patients reported facial pain and it was unsurprising that the facial pain is of a multifactorial etiology.

\section{CONCLUSIONS}

The age 21- 30 years consider the high-risk age group concerning TMDs in Mosul City. TMJ sounds were the most frequent symptoms, while the ITF were the most frequent sign, no sex difference in both groups. Severe symptoms and signs represented a high percentages ( AiII $51.1 \%$, DiIII $34.4 \%$ ) in patients with TMDs at Mousl City. This means that the patients concerning the treatment at the late stages of the disease. Again no sex difference between the two groups.

\section{REFERENCES}

1. Carlsson G, Magnusson T. Management of Temporomandibular Disorders in the General Dental Practice. Quintessence publishing CO.INC. 1999.

2. Hussein S. Myofascial pain dysfunction syndrome in Iraq, symptom distribution among 300 patients. Iraqi Dental J. 1985; 12: 165-173.

3. Agerberg G, Carlsson G. Functional disorders of the masticatory system IDistribution of the symptoms according to 
age and sex as judged from investigation by questionnaire. Acta Odontolo Scan. 1972; 30; 597.

4. Helkimo M. Epidemiological survey of dysfunction of the masticatory system. Cited in: Temporomandibular Function and Dysfunction. Ed: G.A. zarband Carlsson. Munksgaard, Copenhagen.1979.

5. Solberg W, Woo M, Houston B. Prevalence of mandibular dysfunction in young adu1ts. JADA .1979; 98: 25.

6. Grosfeld O, Jackowska M, Czarnecka B. Results of epidemiological examination of the temporomandibular joint in adolescents and young adults. J Oral Rehabl. 1985; 12: 95.

7. Gazit E, Latberman M, Eini R, Hirch N, Strfanty V, Fuschs C, Lios P. Prevalence of mandibular dysfunction 1n 10-18 years old Israeli school childeren. J Oral Rehabl. 1984; 11: 307.

8. Helkimo M. Studies on function and dysfunction of the masticatory system 4. Age and sex distribution of the symptoms of the dysfunction of the masticatory system in Lapps in the north Finland. Acta Odonto Scan. 1974a; 32: 225.

9. Hanson T, Nilner M. Astudy of the occurrence of the symptoms of the disease of the temporomandiblar joint, masticatory muscles and related structures. $J$ Oral Rehbal. 1975; 2: 313.

10. Magnussson T. Prevalence of the recurrent headache and mandibular dysfunction in patients with unsatisfactory complete dentures. Comm Dent and Oral Epidem. 1980: 8-159.

11. Sheref B. Temopromandibulae disorders among asample of 15-19 year old secondary school adolescents in Baghdad - Iraq. Thesis for Master degree in Oral Medicine, University of Baghdad; 1991.

12. Abdullah B. Temopromandiblar disorders among sample of Mosul university students. Thesis for Master degree in Oral Medicine, University of Baghdad; 1992.

13. Helkimo M. Studies on function and dysfunction of the masticatory system .II index for anamenstic and clinical dysfunction and occlusal state. Swed dental J. 1974: 101-121.

14. Droukas B, Lindee C, Carlsson A. Relationship between the occlusal factors, signs and symptoms of mandibular dysf- unction. Acta Odontol Scad. 1984; 42: 277-283.

15. Greenberg M, Glick M. Burkets Oral Medicine, Diagnosis and Treatment 10 ed., BC Decker INC. 2003.

16. Kaye L, Moran J, Fritz M. Statistical analysis of an urban population of 236 patients with head and neck pain, patients symptomatology. J Periodontol. 1979; 50(2): 59.

17. Cooper B, Alleva M, Cooper D, Lucente F. Myofacial pain dysfunction syndrome an analysis of 476 patients. Laryngoscope. 1986; 96: 1099.

18. Gelb H, Calderone J, Gross S, Kantor M. The role of the dentists and the otolaryngologist in evaluating temporomandibulae joint syndrome. J Prosth Dent. 1967; 18: 497.

19. Bush F, Whitechill J, Martelli M. Pain assessment in temporomandiblar disorders. $J$ Crainomandibular Pract. 1989; 7: 137.

20. Bush F, Dolwick M, The Temporomandiblar Joint and Related Disorder. $J B$ Lippincott company. 1995.

21. Thomson H. Mandibular joints pain, survey of 100 treated cases. Br Dent J. 1959; 107: 243.

22. Cacchiotti D, Plesho A, Bianchi P, Mcneill C. Signs and symptoms in asample with and without temporomandibular disoreder. J Craniomandibular disorder Facial Oral Pain.1991; 5: 167.

23. Blasberg B, Chambers A. Temporomandibular pain and dysfunction syndrome associated with generlized muscloskeletal pain, a retrospective study. $J$ Rheumatol. 1988; 19(16): 87.

24. Rothwel P. Symtoms of temporomandibular pain dysfunction in 400 patients, time to revise the classic profile. J Dent. 1987; 15-6.

25. Koidis $\mathrm{P}$, Zarif A, Grigoriadou E, Garefis F. Effect of age and sex on crainomandiblar disorders. J Prost Dent. 1993; 69: 93.

26. Sciffman E, Friction J, Haley D, Pand Shapiro B. The prevalence and treatment needs of the subject with temopromandibular disorders. JADA. 1990; 120: 195303.

27. Hole B, Hole L. Frequency and distribution of myofacial pain dysfunction syndrome in population of 25 yaers old, Comm Dent Oral Epidemol. 1979; 7: 357-360. 